\title{
Enzyme-linked Immunosorbent Spot Assay
}

National Cancer Institute

\section{Source}

National Cancer Institute. Enzyme-linked Immunosorbent Spot Assay. NCI Thesaurus. Code C102632.

A highly sensitive immunoassay capable of detecting secreted materials from individual cells upon activation. If the material of interest is secreted in response to a particular stimulus, then the material will bind to a specific immobilized antibody. Binding is then verified and visualized by applying other antibodies that have been tagged in some way. 